\title{
Thérèse Malachy, Le théâtre dans la cité (Un recueil d'articles)
}

\section{Gabriella Bosco}

\section{(2) OpenEdition}

1 Journals

\section{Edizione digitale}

URL: http://journals.openedition.org/studifrancesi/8425

DOI: $10.4000 /$ studifrancesi.8425

ISSN: 2421-5856

\section{Editore}

Rosenberg \& Sellier

\section{Edizione cartacea}

Data di pubblicazione: 1 mai 2009

Paginazione: 225

ISSN: 0039-2944

\section{Notizia bibliografica digitale}

Gabriella Bosco, «Thérèse Malachy, Le théâtre dans la cité (Un recueil d'articles)», Studi Francesi [Online] 157 (LIII | I) | 2009, online dal 30 novembre 2015, consultato il 12 janvier 2021. URL: http:// journals.openedition.org/studifrancesi/8425 ; DOI: https://doi.org/10.4000/studifrancesi.8425

Questo documento è stato generato automaticamente il 12 janvier 2021.

\section{(c) $(1) \&$}

Studi Francesi è distribuita con Licenza Creative Commons Attribuzione - Non commerciale - Non opere derivate 4.0 Internazionale. 


\title{
Thérèse Malachy, Le théâtre dans la cité (Un recueil d'articles)
}

\author{
Gabriella Bosco
}

\section{NOTIZIA}

THÉRÈSE MALACHY, Le théâtre dans la cité (Un recueil d'articles), Paris, Nizet, 2008, pp. 230.

1 Il volume, che raccoglie articoli precedentemente pubblicati in riviste specializzate, intende essere un omaggio al filosofo e studioso di teatro Henri Gouhier, maestro dell'Autrice. Il filo conduttore, simile a quello che ispirò i lunghi anni di insegnamento di Thérèse MALACHY all'Università Ebraica di Gerusalemme, è dato dalla volontà di individuare la specificità del testo scenico, visto nell'ottica dei rapporti che esso instaura con la realtà.

2 Gli articoli sono divisi in tre sezioni: quelli che si occupano di pratica teatrale, quelli che analizzano il fenomeno della riscrittura a teatro, e quelli che affrontano l'aspetto socio-storico di certe opere. Nella prima parte («La pratique du théâtre», pp. 9-63), l'A. s'interroga sul senso del testo sottoposto alla prova della scena o che porta in sé la propria messa in scena: due articoli fungono da introduzione agli altri della sezione: «De l'écrit au représenté: le texte comique» e «L'anatomie de l'acteur comique». Seguono studi consacrati ai Molière di Vitez, al Britannicus di Racine, a Le Ravissement de Scapin di Paul Claudel, a spazio scenico e spazio verbale in Michel de Ghelderode, a Samuel Beckett e alla messa in scena della Shoah.

3 La seconda sezione («Palimpsestes», pp. 65-133) indaga l'attrazione determinata da certi testi fondatori e le loro riscritture periodicamente fluttuanti. Gli articoli qui raccolti si occupano dell'Esther di Racine nei suoi rapporti con l'Antico Testamento; di Athalie nell'incrocio delle tradizioni; del Don Giovanni Tenorio o sia Il dissoluto di Carlo Goldoni, una tragi-commedia dimenticata; del Don Juan ou les Amants chimériques di Michel de Ghelderode; dell'Ornifle di Anouilh; del mito greco in Francia prima e dopo l'Occupazione; dell'Electre di Marguerite Yourcenar, mito in divenire; dell'Antigone 
ancora di Anouilh, deviazione del tragico; e, sempre di Anouilh, del Pauvre Bitos, che rappresenta l'esplosione teatrale di un mito.

4 La terza e ultima parte («Politique, histoire, société», pp.135-227) si occupa delle corrispondenze tra un determinato clima sociale e le sue ripercussioni sul teatro. Thérèse Malachy raccoglie qui articoli dedicati alla Celestina, ai rapporti di Molière con il potere, al problema della libertà da Corneille a Molière, al Lorenzaccio, alle strutture comiche da Molière a Chaplin, a Georges de Porto-Riche visto come possibile Racine ebreo, a La Guerre de Troie n'aura pas lieu di Jean de Giraudoux, all'idea di felicità nel teatro di Anouilh, al senso di colpa senza Dio in Samuel Beckett. Il volume si chiude con una lettura politica di En attendant Godot. 